Interestingly, freedom from seizures was almost identical, whether patients were treated first with a standard drug or a new drug.

The recent guidelines from the National Institute for Health and Clinical Excellence (NICE) on newer drugs for epilepsy in adults is therefore vague on the management of refractory epilepsy because of a lack of data comparing the new drugs with each other or with standard drugs, either as monotherapy or combination therapy. ${ }^{8}$ NICE recommends that combination therapy should be considered only when attempts at monotherapy have not resulted in freedom from seizures but gives no guidance on the number of attempts at monotherapy or which combination to try. I estimate that the bewildered general neurologist or physician can choose from up to 13 options for monotherapy and 91 options for combination therapy. This is clearly an unsatisfactory situation for patients and physicians alike.

Doctors tend to opt for their own favourite combinations, influenced by marketing pressures or based on speculative concepts of different mechanisms of drug action or synergy-concepts that originally led to the subsequently discredited combined capsules of phenobarbital and phenytoin. ${ }^{9}$ Switching to alternative monotherapy is more time consuming and requires careful clinical monitoring. It is easier to add a second drug, and if there is some clinical improvement, as occurs in up to one third of patients, it is tempting but possibly erroneous to assume that improvement is due to the combination rather than to the second drug. Such thinking perpetuates the phenomenon and scale of polytherapy. ${ }^{2}$ Furthermore, combination therapy increases the risk of side effects, including teratogenicity, ${ }^{10}$ especially if the drugs are similar (for example, carbamazepine and oxcarbazepine) or if they interact (for example, lamotrigine and valproate or carbamazepine).

In treating epilepsy in childhood, similar problems arise. Compared with adults, however, children have a much higher incidence of idiopathic generalised epilepsy syndromes, for which some standard or new drugs, such as carbamazepine or vigabatrin, may be inappropriate. In addition, fewer of the new drugs have been licensed for use in children, and comparative data on different drug treatments are even scarcer. ${ }^{11}$

The pharmaceutical industry finances $90 \%$ of all clinical trials in the UK. ${ }^{12}$ But industry has no interest in supporting large scale, long term pragmatic trials that might provide evidence to reduce much unnecessary polytherapy and therefore restrict the market for many of the newer drugs. Academics specialising in epilepsy will therefore have to clarify, through research, how much real progress has been made in managing resistant epilepsy since the era of phenobarbital and phenytoin.

Edward Reynolds honorary senior lecturer

(reynolds@buckles.u-net.com)

Institute of Epileptology, King's College, London SE5 6PJ

Competing interests: None declared.

Reynolds EH, Chadwick D, Galbraith AW. One drug (phenytoin) in the treatment of epilepsy. Lancet 1976;1:923-6.

2 Reynolds EH, Shorvon SD. Monotherapy or polytherapy for epilepsy? Epilepsia 1981;22:1-10.

3 Mattson RH, Cramer JA, Collins JF, Smith DB, Delgado-Escueta AV, Browne TR, et al. Comparison of carbamazepine, phenobarbital, phenytoin and primidone in partial and secondarily generalised tonic-clonic seizures. N Engl J Med 1985;313:145-51.

4 Heller AJ, Chesterman P, Elwes RDC, Crawford P, Chadwick D, Johnson AL, et al. Phenobarbitone, phenytoin, carbamazepine or sodium valproate for newly diagnosed adult epilepsy: a randomised comparative monotherapy trial. J Neurol Neurosurg Psychiatry 1995;58:44-50.

5 Schmidt D. Two anti-epileptic drugs for intractable epilepsy with Schmidt D. Two anti-epileptic drugs for intractable epilepsy with
complex-partial seizures. I Neurol Neurosurg Psychiatry 1982;45: 1119-24.

6 Beghi E, Gatti G, Tonini C, Ben-Menachem E, Chadwick DW, Nikanorova $\mathrm{M}$, et al. Adjunctive therapy versus alternative monotherapy in patients with partial epilepsy failing on a single drug: a multi-centre, randomised, pragmatic controlled trial. Epilepsy Res 2003;57:1-13.

7 Kwan P, Brodie MJ. Early identification of refractory epilepsy. $N$ Engl J Med 2000;342:314-9.

National Institute for Clinical Excellence. Newer drugs for epilepsy in adults. NICE Technology Appraisal Guidance 76. London: NICE, 2004.

9 Macdonald RL. Is there a mechanistic basis for rational polypharmacy? Epilepsy Res 1996;11:79-93.

10 Morrow JI, Russell A, Gutherie E, Parsons L, Robertson I, Waddell R, et al Malformation risks of anti-epileptic drugs in pregnancy: a prospective study from the UK epilepsy and pregnancy register. J Neurol Neurosurg study from the UK epilepsy and pregnancy register. J Neurol Neurosurg
Psychiatry 2005. Published online 12 Sep 2005. doi: 10.1136 . jnnp.2005.074203.

11 De Silva M, MacArdle B, McGowan M, Hughes E, Stewart J, Neville BGR, et al. Randomised comparative monotherapy trial of phenobarbitone, phenytoin, carbamazepine, or sodium valproate for newly diagnosed childhood epilepsy. Lancet 1996;347:709-13.

12 Ferner RE. The influence of big pharma. BMJ 2005;330:855-6.

\title{
The burden of chronic kidney disease
}

\author{
Is rising rapidly worldwide
}

$\mathrm{T}$ he number of patients with chronic kidney disease worldwide is rising markedly. ${ }^{1}$ In the United Kingdom, the annual incidence of end stage renal disease is around 100 per 1000000 population. ${ }^{2}$ This incidence has doubled over the past decade and is expected to continue to rise by $5-8 \%$ annually, but it remains well below the European average (around 135/1000 000) and that of the United States $(336 / 1000000){ }^{3}$

Disparities in the incidence of end stage renal disease within and between developed countries reflect racial and ethnic diversity. In the US, the annual incidence is 256/1000 000 in white people compared with 982/1 000000 in African-Americans. ${ }^{3}$ In Australia, the incidence in white people is comparable to that in the UK (94/1 000000$)$, but the incidence in aboriginals is $420 / 1000000$.

The rise in end stage renal disease worldwide most probably reflects the global epidemic of type 2 diabetes and the ageing of the populations in developed countries, with a higher incidence in elderly people (the annual incidence in people over 65 in the UK is greater than $350 / 1000000,{ }^{2}$ and in the US it is greater than $1200 / 1000000){ }^{3}$. The number of people with diabetes worldwide, currently around 154 million, is set to double within the next 20 years, and the increase will be 
most notable in the developing world, where the number of patients with diabetes is due to reach 286 million by $2025 .^{4}$

The cost of treating patients with end stage renal disease is substantial and poses a great challenge to provision of care. In Europe, less than $0.1 \%$ of the population needs renal replacement therapy, which accounts for $2 \%$ of the healthcare budget. In the US, the annual cost of treatment for end stage renal disease is expected to reach $\$ 29 \mathrm{bn}$ ( $£ 17 \mathrm{bn}$; €25bn) by 2010 . ${ }^{1}$ Few countries will be able to meet these growing medical and financial demands; five countries-the US, Germany, Italy, Japan, and Brazil-with 12\% of the world's population-already treat more than half of the world's people with end stage renal disease. ${ }^{5}$

More than 100 developing countries, together with a population in excess of 600 million, do not have any provision for renal replacement therapy. ${ }^{5}$ Consequently, more than a million people die every year worldwide from end stage renal disease. The huge disparity in the prevalence of this disease between the industrialised world and emerging nations reflects different priorities for health care and the inadequacy of resources allocated to renal replacement therapy.

Programmes to detect chronic kidney disease, linked to comprehensive primary and secondary prevention strategies, are needed urgently. Successful examples of such programmes have been shown in developed and developing countries; in the Netherlands, the prevention of renal and vascular end stage disease (PREVEND) screening programme detected albuminuria in around $6-7 \%$ of the population of the city of Groningen. ${ }^{6}$ In India's Chennai province ${ }^{7}$ and in the aboriginals of the northern Australian territories, ${ }^{8}$ the detection of chronic kidney disease and predisposing conditions such as diabetes and hypertension led to effective interventions. In Singapore, the national kidney foundation has launched a nationwide comprehensive screening and detection programme for chronic kidney disease. ${ }^{9}$

Patients with end stage renal disease comprise only a small percentage of people with chronic kidney disease. $^{10}$ The total prevalence of chronic kidney disease may be 50 times that of treated end stage renal disease. In the US, up to $11 \%$ of the population (19 million) may have chronic kidney disease.$^{10}$ Surveys in Australia, Europe, and Japan show that the prevalence of at least some degree of this chronic disease is $6-16 \% .{ }^{11}$ Population based studies show that $6-7 \%$ of the population has albuminuria (or microalbuminuria) and around $0.6-0.7 \%$ proteinuria. ${ }^{11}$ The prevalence of chronic kidney disease is even higher $(16 \%)$ when those at risk, including relatives of patients with the disease, are screened. ${ }^{12}$

Mass population screening for chronic kidney disease with tests such as urinalysis is neither practical nor likely to be successful or cost effective. Yet most clinical practice guidelines now recommend identifying those at risk-people with hypertension, diabetes, obesity, and other predisposing conditions or medicines as well as older people and relatives of patients with chronic kidney disease. ${ }^{13}$

Screening of urine samples with dipsticks for albuminuria and proteinuria is useful as long as it is confirmed by quantitative spot urine analysis for albumin:creatinine ratio or protein:creatinine ratio. ${ }^{13}$ These tests are more accurate than those based on the analysis of 24 hour urine collections in view of the inaccuracies of the latter. Serum creatinine is a readily available and reliable indicator of chronic kidney disease but it may be altered by a variety of factors, and renal function may be compromised considerably before serum creatinine concentrations rise. Reporting of serum creatinine is nowadays often linked to that of a calculated glomerular filtration rate.

Structured and well resourced primary prevention programmes based on reducing the risk factors for chronic kidney disease could make a big difference. ${ }^{11}$ Patients should be encouraged to give up smoking and to lose weight. Secondary prevention depends on tight control of blood pressure (to less than 130/80 mm $\mathrm{Hg})^{9}{ }^{14}$ and the use of angiotensin converting enzyme inhibitors and angiotensin II receptor blockers concomitantly to reduce proteinuria (to less than $1 \mathrm{~g} / 24$ hours). Guidelines also recommend strict control of diabetes with an $\mathrm{HbAlc}$ level of around $7 \% .{ }^{13}$ Statins may benefit patients with chronic kidney disease through preventing arteriosclerosis. Such a multifactorial approach to risk reduction may slow or even reverse declining renal function. ${ }^{15}$

Rizwan A Hamer specialist registrar

A Meguid El Nahas professor

M.el-nahas@sheffield.ac.uk

Sheffield Kidney Institute, Sheffield Teaching Hospitals NHS

Foundation Trust, Northern General Hospital, Sheffield S5 7AU

Competing interests: None declared.

1 Lysaght MJ. Maintenance dialysis population dynamics: current trends and long-term implications. J Am Soc Nephrol 2002;13:37-40.

2 Ansell D, Feest T, eds. UK renal registry report 2004. Bristol: UK Renal Registry, 2004.

3 United States Renal Data System (USRDS). 2004 annual report. Am J Kidney Dis 2005;45(suppl 1).

4 King H, Auburt RE, Herman WH. Global burden of diabetes, 1995-2025: prevalence, numerical estimates, and projections. Diabetes Care 1998; 21:1414-31.

5 Lacson Jr E, Kuhlmann MK, Shah K, Yoshino M, Levin NW. Outcomes and economics of ESRF. In: El Nahas AM, ed. Kidney diseases in the developing world and ethnic minorities. New York: Taylor and Francis, 2005: 15-37.

6 Hillege HL, Janssen WM, Bak AA, Diercks GF, Grobbee DE, Crijns HJ, et al,. Prevend Study Group. Microalbuminuria is common, also in a nondiabetic, nonhypertensive population, and an independent indicator of cardiovacular risk factors and cardiovascular morbidity.J Intern Med of cardiovascular

7 Datta M, Mani MK. Community-based approach to prevention of chronic kidney disease: the Chennai experience. In: El Nahas AM, ed. Kidney diseases in the developing world and ethnic minorities. New York: Taylor and Francis, 2005:395-409.

8 Hoy WE, Chennakesavan SK, McDonald SP, Cass A, Singh GR, Bertram JF, Hughson MD. Chronic kidney disease in Aboriginal Australians. In: El Nahas AM, ed. Kidney diseases in the developing world and ethnic minorities. New York: Taylor and Francis, 2005:305-33.

9 Sylvia PB, Ramirez SIH, Stephen IHH, McClellan W. Taking a public health approach to the prevention of end-stage renal disease: the NKF Singapore program. Kidney Int 2003; (suppl 63):S61-5

10 Coresh J, Astor BC, Greene T, Eknoyan G, Levey AS. Prevalence of chronic kidney disease and decreased kidney function in the adult US population: third national health and nutrition examination survey. Am J Kidney Dis 2003;41:1-12.

11 El Nahas AM, Bello AK. Chronic kidney disease: the global challenge. Lancet 2005;365:331-40.

12 Brown WW, Peters RM, Ohmit SE, Keane WF, Collins A, Chen S-C, et al. Early detection of kidney disease in community settings. The kidney early evaluation programme (KEEP). Am J Kidney Dis 2003;42:22-35.

13 National Kidney Foundation. K/DOQI clinical practice guidelines for chronic kidney disease: evaluation, classification and stratification. $\mathrm{Am} \mathrm{J}$ Kidney Dis 2002;39(suppl 1):1-246.

14 National Kidney Foundation. K/DOQI clinical practice guidelines on hypertension and anti-hypertensive agents in chronic kidney disease. $\mathrm{Am}$ J Kidney Dis 2004;43(suppl 2):1-290.

15 Ruggenenti P, Schieppati A, Perico N, Codreanu I, Peng L, Remuzzi G. Kidney prevention recipes for your office practice. Kidney Int 2005; 67(suppl 94):S136-41. 